\title{
SPECTRUM OF BONE MARROW DIAGNOSES AND THEIR CLINICO-HAEMATOLOGICAL PROFILE
}

\author{
R. K. Banashree Devi' 1 , Ksh. Achouba Singh², Anil Irom³ 3 , Y. Mohen Singh 4
}

${ }_{1}^{1}$ Associate Professor, Department of Pathology, Jawaharlal Nehru Institute of Medical Sciences (JNIMS), Imphal, Manipur, India. ${ }^{2}$ Associate Professor, Department of Endocrinology, Jawaharlal Nehru Institute of Medical Sciences (JNIMS), Imphal, Manipur, India. ${ }^{3}$ Assistant Professor, Department of Medicine, Jawaharlal Nehru Institute of Medical Sciences (JNIMS), Imphal, Manipur, India. ${ }^{4}$ Professor and HOD, Department of Pathology, Jawaharlal Nehru Institute of Medical Sciences (JNIMS), Imphal, Manipur, India. ABSTRACT

\section{BACKGROUND}

The purpose of this study was to analyse the spectrum of bone marrow aspiration and biopsy results and their clinicohaematological profile.

\section{MATERIALS AND METHODS}

This retrospective descriptive study was conducted from $1^{\text {st }}$ September 2017 to $31^{\text {st }}$ August 2018. All bone marrows examined during his period were included. Demographic profile including age, sex, clinical history etc. were analysed from the records available in the bone marrow register which is maintained in Pathology department, Jawaharlal Nehru Institute of Medical Sciences, Imphal. A total of 94 bone marrows were included. Appropriate statistical analysis was applied.

\section{RESULTS}

Check marrows (25.88\%) was the most common reason for bone marrow examinations. Acute leukaemias (18.82\%) were the most haematological disorder encountered followed by nutritional dual deficiency anaemia (5.88\%).

\section{CONCLUSION}

The results of this study will assist in future planning for installation of special tests such as flow cytometry and molecular laboratory. Finally bone marrow aspiration (BMA) and bone marrow biopsy (BMB) are two separate but complimentary techniques which are required for diagnosis of various haematological disorders.

\section{KEY WORDS}

Bone Marrow Aspirate (BMA), Bone Marrow Biopsy (BMD), Acute Leukaemias, Check Marrows.

HOW TO CITE THIS ARTICLE: Devi RKB, Singh KA, Irom A, et al. Spectrum of bone marrow diagnoses and their clinicohaematological profile. J. Evolution Med. Dent. Sci. 2018;7(45):4825-4828, DOI: 10.14260/jemds/2018/1075

\section{BACKGROUND}

Bone marrow examination is indicated as an initial investigation for diagnosis of various haematological disorders like acute leukaemias, myelodysplastic syndrome etc. It is complimentary for diagnosis of megaloblastic anaemia, investigations of pyrexia of unknown origin, anaemias refractory to treatment, other patients with comorbidities like diabetes mellitus, thyroid abnormalities, HIV infections etc. presenting with haematological abnormalities which cannot be explained by the disease per se or the treatment. Bone marrow examination is also required for staging of certain non-haematological and lymphoproliferative lesions ${ }^{1-3}$ for purpose of treatment and prognostication as bone marrow involvement is indicative of advanced stage of the neoplasm. It is mandatory for both diagnosis as well as confirmation of certain myeloproliferative neoplasms. 4,5 The present study was conducted to evaluate the bone marrows performed during the study period and to correlate with their clinicohaematological profile.

'Financial or Other Competing Interest': None.

Submission 11-10-2018, Peer Review 23-10-2018,

Acceptance 26-10-2018, Published 05-11-2018.

Corresponding Author:

Ksh. Achouba Singh,

Uripok Bachaspati Maning Leikai,

Imphal-795001, Manipur, India.

E-mail: drachoubasingh@yahoo.com

DOI: $10.14260 /$ jemds $/ 2018 / 1075$

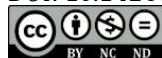

Aims \& objectives- Aims \& objective of this study was to find out-

1. The spectrum of bone marrow aspiration and biopsy results

2. To correlate with their clinico-haematological profile.

\section{MATERIALS AND METHODS}

The retrospective descriptive study. It was conducted in the Department of Pathology, Jawaharlal Nehru institute of Medical sciences, Imphal which is a tertiary referral hospital in the state of Manipur. The study was conducted during the one year period -from $1^{\text {st }}$ September 2017 to $31^{\text {st }}$ August 2018. During this period, a total of 94 bone examinations were conducted in the Department of Pathology Jawaharlal Nehru institute of Medical sciences, Imphal. The secondary data available in the register were analysed. Appropriate statistical analysis were employed.

\section{Inclusion Criteria}

All cases where the material is sufficient for analysis were included in the study.

\section{RESULTS}

A total of 94 bone marrow examination were done during the study period. Out of these, 9 cases were inadequate or extremely haemodilute for comment and these were excluded from analysis. Of the 85 reportable cases, there were 46 males and 39 males giving a male: female ratio of 1.18:1. 18 paediatric cases were included in the study. Check marrows (25.88\%) after specified therapy constituted the 
most frequent reason for bone marrow examination followed by acute leukaemias (18.82\%) (Table 1). Anaemia (31.76\%) was the commonest presenting features (Figure 1). Among the acute leukaemia cases, there were 10 male and 6 female patients ( $\mathrm{M}: \mathrm{F}=1.6: 1$ ), age ranged from 4 years to 72 years. There were $56.25 \%$ cases of ALL and $44.75 \%$ cases of AML (Figure 2). Among the ALL cases, majority (77.8\%) of the cases were in paediatric age group (Figure 3) whereas all of AML cases was adults (Figure 3). Most cases of ALL had $\geq 80$ $\%$ blasts in the bone marrow. 2 cases each of acute promyelocytic leukaemia and AML M2 were included. A case of smouldering multiple myeloma with $18 \%$ plasma cells was encountered in a patient of diabetes mellitus. Out of the total 37 non neoplastic bone marrow diagnoses, there were 20 males and 17 females. Age ranged from 17 to 87years. Among the nonneoplastic conditions, dual deficiency nutritional anaemia, (13.89\%) was the most frequent benign diagnosis followed by megaloblastic anaemia and iron deficiency anaemia (11.11\% each) encountered. 4 HIV infected cases on antiretroviral treatment (ART) were also included. Three of them showed presence of intracellular organisms about the size of 2-4 $\mu \mathrm{m}$, and non-capsulated. However the species could not be identified as no growth were detected on culture. Significant dysplasia was noted in all cases. Among the check marrows, 9 cases of B-ALL, 4 cases of AML1 case each of TALL and CML-BC. 18 paediatric cases were included in the series, of which check marrows (50\%) was the commonest followed by acute lymphoblastic leukaemia (38.9\%) (Figure 6). Among acute leukaemias, males were more commonly affected (Figure 7). In 5 cases, diagnosis was possible only on trephine biopsy. These included 2 cases of bone marrow aspirate smears for review. These were diagnosed as AML M4 and hemophagocytic lymphohistiocytosis on BMA smears in some private laboratory. Consequent upon review of these smears, reaspiration with bone marrow biopsies were done. Final diagnoses were intravascular large B cell lymphoma and Langerhans cell histiocytosis which were confirmed on immunohistochemical staining with CD 20, CD 3, and CD1a respectively.

\begin{tabular}{|c|c|c|c|}
\hline & Diagnosis & Number & $\%$ \\
\hline 1. & Check marrow & 22 & 25.88 \\
\hline 2. & Acute leukaemia & 16 & 18.82 \\
\hline 3. & Normal reacting marrow & 5 & 5.88 \\
\hline 4. & Dual deficiency anaemia & 5 & 5.88 \\
\hline 5. & Iron deficiency anaemia & 4 & 4.7 \\
\hline 6. & Megaloblastic anaemia & 4 & 4.7 \\
\hline 7. & Plasma cell neoplasm & 4 & 4.7 \\
\hline 8. & Hypercellular bm & 3 & 3.52 \\
\hline 9. & Lymphoma & 3 & 3.52 \\
\hline 10. & HIV infected cases & 3 & 3.52 \\
\hline 11. & Variably cellular BM & 3 & 3.52 \\
\hline 12. & Necrosis & 2 & 2.35 \\
\hline 13. & Erythroid hyperplasia & 2 & 2.35 \\
\hline 14. & Hypocellular BM & 2 & 2.35 \\
\hline 15. & Staging marrow & 2 & 2.35 \\
\hline 16. & Plasmacytosis & 2 & 2.35 \\
\hline 17. & Hemophagocytosis & 1 & 1.17 \\
\hline 18. & Langerhans cell histiocytosis & 1 & 1.17 \\
\hline 19. & Myelofibrosis & 1 & 1.17 \\
\hline & Total & 85 & 100 \\
\hline
\end{tabular}

\begin{tabular}{|r|c|c|c|}
\hline & Diagnosis & Number & Percentage \\
\hline 1. & Dual deficiency anaemia & 5 & 13.89 \\
\hline 2. & Normal reacting marrow & 5 & 13.89 \\
\hline 3. & Iron deficiency anaemia & 4 & 11.11 \\
\hline 4. & Megaloblastic anaemia & 4 & 11.11 \\
\hline 5. & Hypercellular BM & 3 & 8.33 \\
\hline 6. & HIV infected cases on ART & 3 & 8.33 \\
\hline 7. & Variably cellular BM & 3 & 8.33 \\
\hline 8. & Necrosis only & 2 & 5.56 \\
\hline 9. & Erythroid hyperplasia & 2 & 5.56 \\
\hline 10. & Hypocellular BM & 2 & 5.56 \\
\hline 11. & Plasmacytosis & 2 & 5.56 \\
\hline 12. & Hemophagocytosis & 1 & 2.77 \\
\hline & Total & $\mathbf{3 7}$ & $\mathbf{1 0 0}$ \\
\hline
\end{tabular}

Table 2. Spectrum of Benign Bone Marrow Diagnoses

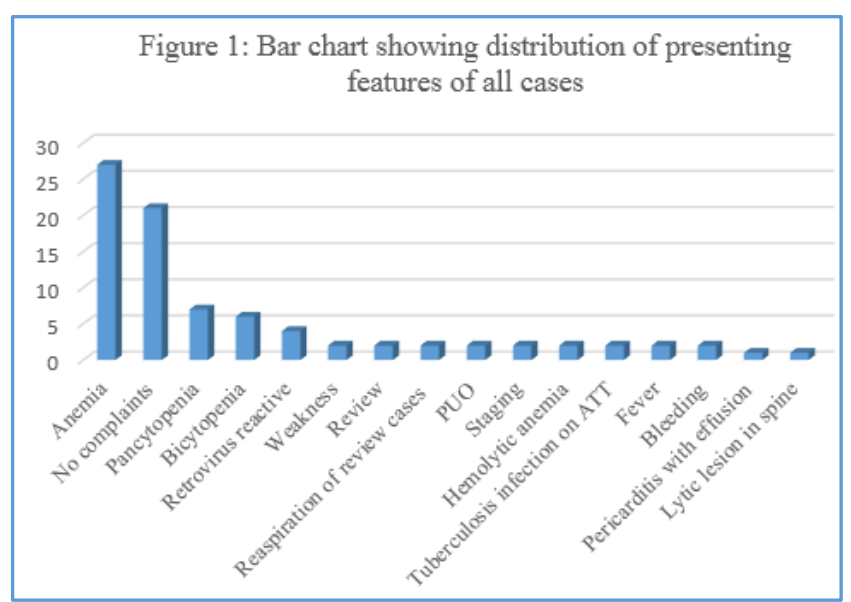

Figure2: Pie chart showing distribution of acute leukemias

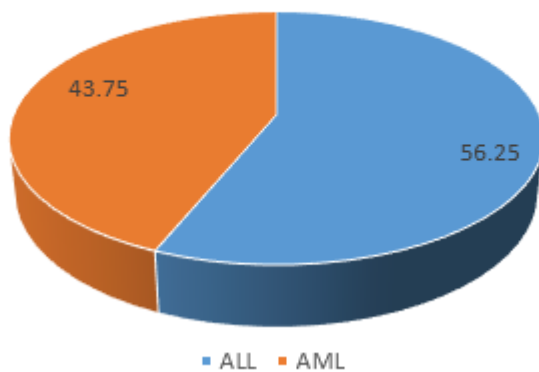

Figure 3: Bar chart showing age distribution of in ALL cases

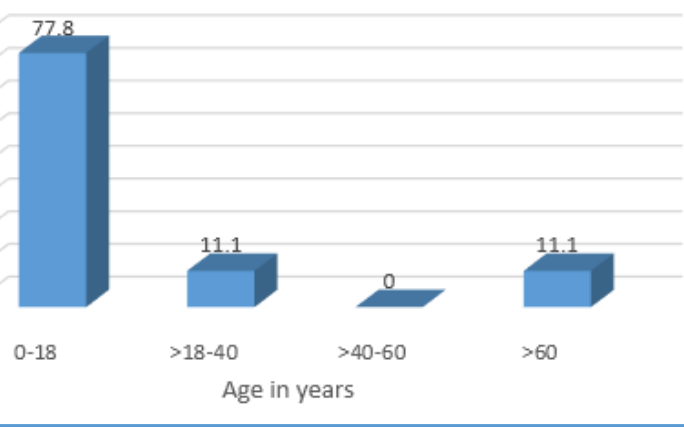




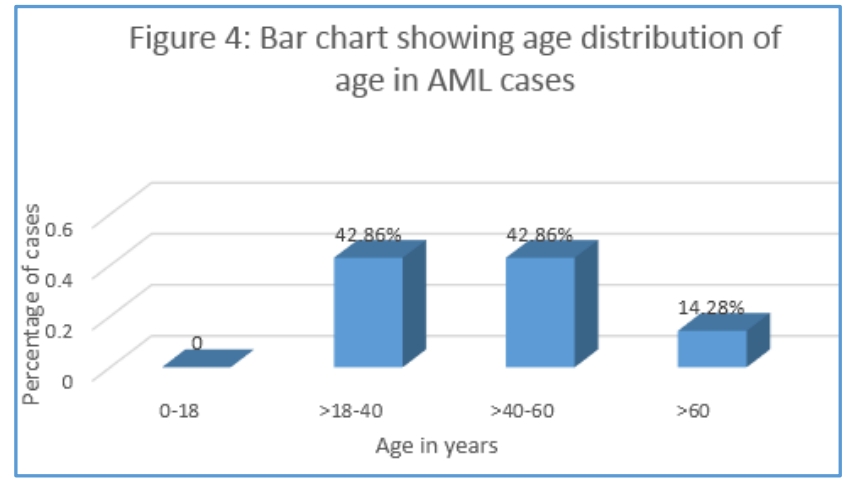

Figure 5: Bar chart showing percentage of blasts in the bone marrow in ALL cases

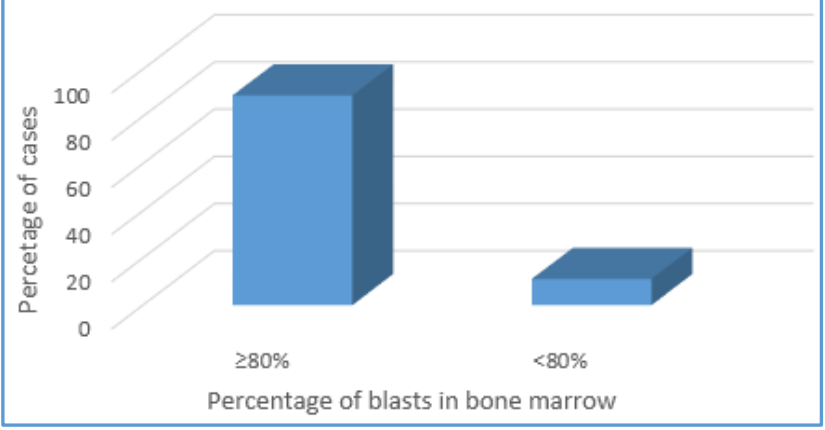

Figure 6: Bar chart showing spectrum of pediatric bone marrow diagnoses
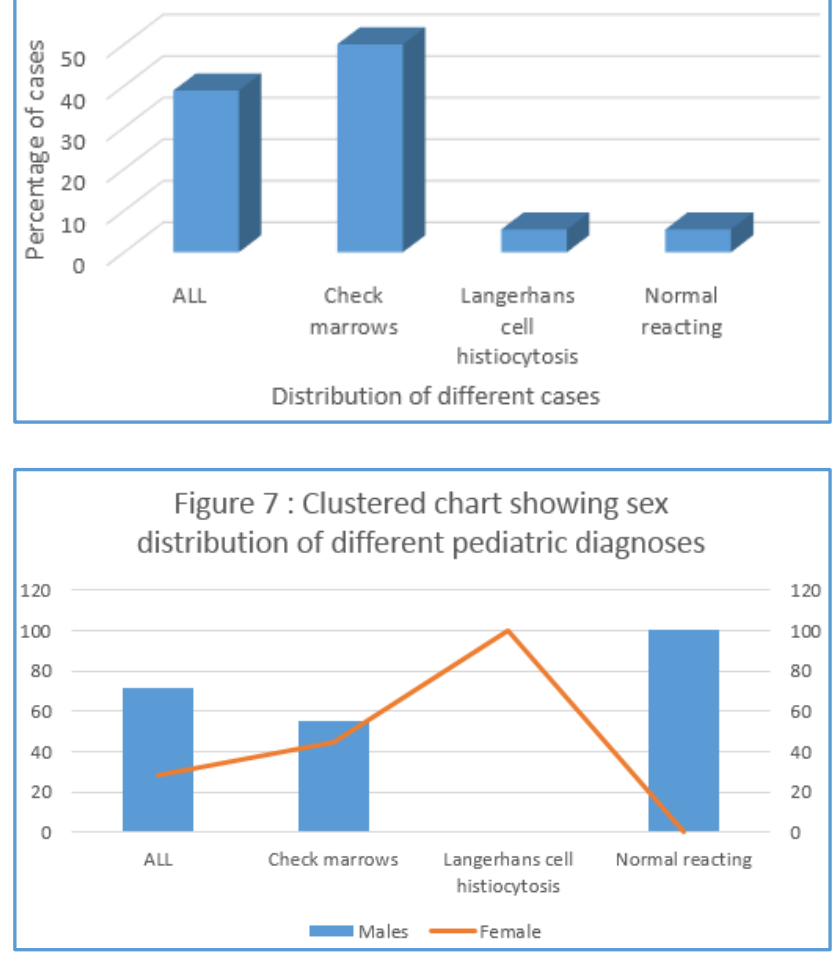

\section{DISCUSSION}

In the present study, the commonest bone marrow diagnosis was acute leukaemia followed by dual deficiency anaemia and hypoplastic marrow. However in the series of Bashir $\mathrm{N}$ et al, megaloblastic anaemia was the most frequent followed by dual deficiency anaemia. ${ }^{6}$ In our study, acute leukaemia was the commonest diagnosis leaving aside check marrows among paediatric cases whereas in the series of Iram Ali et al., iron deficiency anaemia was the frequent. ${ }^{7}$ The difference may be due to the small sample size of our cases and that we do not advise bone marrow for iron deficiency. Majority of our cases of ALL were paediatric age group whereas all cases of AML were adults similar to the findings of Pradhan PKet al.8 2 cases diagnosed as AML M4 and hemophagocytic lymphohistiocytosis on BMA smears in some private laboratory were reviewed. Subsequent on the results of review, re-aspiration with bone marrow biopsy were done. Immunohistochemical staining was performed on BMB and final diagnoses were intravascular large B cell lymphoma and Langerhans cell histiocytosis respectively. Another case of autoimmune haemolytic anaemia, which was direct-Coombstest positive at diagnosis, was referred for persistent anaemia refractory to treatment. BMA was dry tap and imprint smears was acellular. Trephine biopsy revealed diffuse fibrosis. Reticulin stain on BMB showed grade 1 fibrosis with focal grade 2 on a scale of $0-3$. These cases showed the importance of BMB, as seen in the series of Kaur M.et al. ${ }^{9}$ In our series significant dysplasia in hematopoietic lineage were identified in HIV infected cases as reported by different authors. ${ }^{10-12}$ Of these, erythroid dysplasia was the most common, similar to the findings of Tripathi AK.13 1 case of plasmacytosis $(10 \%$ plasma cell) was noted in a case of hypothyroidism. The clonality of the plasma cells could not be assessed as we do not have the facility of flow cytometry in our department. Biopsy of the thyroid gland was refused by the patient. Cases of multiple myeloma associated with plasmacytoma in thyroid gland have been reported 14,15

\section{CONCLUSION}

This study gives an insight into the spectrum of bone marrow diagnoses which will help in future planning for installation of special tests such as flow cytometry and molecular laboratory. Finally bone marrow aspiration (BMA) and bone marrow biopsy (BMB) are two separate but complimentary techniques which are required for diagnosis.

\section{ACKNOWLEDGEMENTS}

We are thankful to the staff of Haematology, Endocrinology and Pathology for their help and support.

\section{REFERENCES}

[1] Armitage JO. Staging non-Hodgkin lymphoma. CA Cancer J Clin 2005;55(6):368-76.

[2] Hutchings M. The role of bone marrow biopsy in Hodgkin lymphoma staging: "to be, or not to be, that is the question"? Leuk Lymphoma 2012;53(4):523-4.

[3] Brisse HJ, McCarville MB, Granata C, et al. Guidelines for imaging and staging of neuroblastic tumors: consensus report from the International Neuroblastoma Risk Group Project. Radiology 2011;261(1):243-57.

[4] Barbui T, Thiele J, Gisslinger H, et al. The 2016 WHO classification and diagnostic criteria for myeloproliferative neoplasms: document summary and in-depth discussion. Blood Cancer J 2018;8(2):15.

[5] Arber DA, Orazi A, Hasserjian R, et al. The 2016 revision to the World Health Organization classification of myeloid neoplasms and acute leukemia. Blood 2016;127(20):2391-405. 


\section{Jemds.com}

[6] Bashir N, Musharaf B, Reshi R, et al. Bone marrow profile in haematological disorders: an experience from a tertiary care centre. International Journal of Advances in Medicine 2018;5(3):608-13.

[7] Ali I, Mir ZH, Qureshi OA, et al. Spectrum of bone marrow aspirations and their clinico-haematological profile in children. International Journal of Contemporary Pediatrics 2015;2(1):25-8.

[8] Pradhan PK, Tiwari SK, Dabke AT, et al. Pattern of leukaemia in Raipur (Madhya Pradesh)--an analysis of 162 cases. Indian J Cancer 1982;19(1):20-3.

[9] Kaur M, Singh Rana AP, Kapoor S, et al. Diagnostic value of bone marrow aspiration and biopsy in routine hematology practice. J Clin Diagn Res 2014;8(8):FC136.

[10] Dhurve SA, Dhurve AS. Bone marrow abnormalities in HIV disease. Mediterr J Hematol Infect Dis 2013;5(1):e2013033.

\section{Original Research Article}

[11] Ramraje SN, Ansari SAH, Kosale S. Diagnostic utility of bone marrow sampling and profile of haematological abnormalities in Indian HIV-infected individuals. IJBC 2016;8(4):117-22.

[12] Sharad AD, Alka SD. Comparison of peripheral smear finding with bone marrow finding in HIV patients. Sch J App Med Sci 2014; 2(2C):711-7.

[13] Tripathi AK, Misra R, Kalra P, et al. Bone marrow abnormalities in HIV disease. J Assoc Physicians India 2005;53:705-10.

[14] Singh K, Kumar P, Pruthy R, et al. Multiple myeloma presenting as thyroid plasmacytoma. Indian J Med Paediatr Oncol 2017;38(4):552-4.

[15] Gilani JA, Iqbal S, Nasreen S, et al. Plasmacytoma of the thyroid gland. J Ayub Med Coll Abbottabad 2011;23(4):131-2. 